Martarelli, C. S., Bertrams, A., \& Wolff, W. (2020). A personality trait-based network of boredom, spontaneous and deliberate mind-wandering. Accepted at Assessment.

The permanent link for this article is https://doi.org/10.1177/1073191120936336.

\title{
A personality trait-based network of boredom, spontaneous and deliberate mind-wandering
}

Corinna S. Martarelli ${ }^{1}$, Alex Bertrams ${ }^{2}$, \& Wanja Wolff ${ }^{2,3}$

${ }^{1}$ Faculty of Psychology, Swiss Distance University Institute, Switzerland

${ }^{2}$ Department of Educational Psychology, University of Bern, Switzerland

${ }^{3}$ Department of Sport Science, University of Konstanz, Germany

Correspondence: corinna.martarelli@,fernuni.ch

\section{Acknowledgements}

We would like to thank Laura Globig, Livio Hardegger, Sina Jossen, and Laura Rotheichner for their help with the translation of the scales and with the collection of data. Moreover, we would like to thank Eiko Fried and two anonymous reviewers for providing helpful comments on an earlier version of the manuscript. 


\title{
A personality trait-based network of boredom, spontaneous and deliberate mind-wandering
}

\begin{abstract}
This article reports the translation into German and validation of two self-report measures of mind-wandering and boredom (the Spontaneous and Deliberate Mind-Wandering Scales; SDMWS; Carriere, Seli, \& Smilek, 2013, and the Short Boredom Proneness Scale; SBPS; Struk, Carriere, Cheyne, \& Danckert, 2017). Confirmatory factor analyses (CFAs) provided support for the original conceptualization of the constructs. To evaluate measurement invariance across samples, data were collected in a German-speaking sample $(n=418)$ and an English-speaking sample $(n=364)$. The results indicated weak measurement invariance. To explore the interplay between mind-wandering and boredom, we performed an exploratory graph analysis (EGA) in the entire sample $(N=782)$, which revealed the structure of relationships between boredom and the two facets of mind-wandering. The results are discussed in the context of theoretical accounts of boredom and mind-wandering.
\end{abstract}

Keywords: deliberate mind-wandering, spontaneous mind-wandering, boredom, confirmatory factor analysis, measurement invariance, exploratory graph analysis, German version 


\section{A personality trait-based network of boredom, spontaneous and deliberate}

\section{mind-wandering}

Sometimes we disengage from the external world. For example, when performing a simple, repetitive task for a prolonged time (e.g., checking whether the reference list of one's manuscript is in line with the APA guidelines), one might get bored. Thoughts might spontaneously begin to wander. One might even deliberately think about something that is more rewarding than looking up the digital object identifier of the forty-seventh reference in the reference list. The above example touches on three ubiquitous human experiences that greatly affect behavior and well-being: boredom, spontaneous mind-wandering, and deliberate mind-wandering.

Mind-wandering has been investigated extensively during the last two decades from a behavioral as well as a neural perspective (see Smallwood \& Schooler, 2006, 2015, for comprehensive reviews). It is a mental state that manifests itself when attention is directed to internally generated thoughts and drifts away from the actual sensory environment (e.g., Mason et al., 2007; Smallwood \& Schooler, 2006). Mind-wandering is ubiquitous and omnipresent: Killingsworth and Gilbert (2010) showed that we spend around half of our daily lifetime mind-wandering.

Parallel to the accumulation of evidence that attests to the high prevalence of mindwandering in everyday life, various heterogeneous conceptualizations of the construct have been proposed. Mind-wandering has been characterized as mental experiences ranging "from attentional lapses to purposeful, task-unrelated planning; from free flowing thought and creative idea generation to highly constrained, perseverative rumination" (Christoff et al., 2018, p. 957). These varied definitions suggest that mind-wandering may not be a unitary construct. In line with this, a recent conceptualization differentiates spontaneous mindwandering from deliberate mind-wandering (e.g., Seli et al., 2018; Seli, Risko, \& Smilek, 2016; see Giambra (1995) for an early distinction between spontaneous and deliberate mind- 
wandering). The former refers to thought that occurs without intention and the latter refers to thought that is controlled.

Intuitively, mind-wandering seems to share similarities with another experience that is omnipresent in everyday life: boredom. Despite its ubiquitous nature, boredom has only recently started to trigger increased interest in psychological research (e.g., Bench \& Lench, 2019; Gomez-Ramirez \& Costa, 2017; Mills \& Christoff, 2018; Mugon, Struk, \& Danckert, 2018; Westgate \& Wilson, 2018; see Bench \& Lench, 2013; Götz, Frenzel, Hall, Nett, Pekrun, \& Lipnevich, 2014 for previous work). Boredom has been defined as a failure of engaging attention with internal and external information (e.g., Eastwood, Frischen, Fenske, \& Smilek 2012) and as a signal to explore behavioral alternatives (e.g., Geana, Wilson, Daw, \& Cohen, 2016; Wolff \& Martarelli, 2020). Engaging attention and sustaining attention directly relate boredom to mind-wandering on a conceptual level. However, surprisingly little empirical research has investigated the two constructs concurrently (but see e.g. Danckert \& Merrifield, 2018; Isacescu, Struk, \& Danckert, 2017). Mind-wandering and boredom both appear to increase with fatigue and time-on-task - for example, in situations in which one is constrained and cannot change activity - and both appear to be associated with several negative consequences such as impaired performance in a primary task (Pattyn, Neyt, Henderickx, \& Soetens, 2008). Moreover, mind-wandering and boredom are generally perceived as being aversive. As a drastic illustration, research shows that some people opt to self-administer mild aversive electric shocks instead of being on their own with their thoughts (Wilson et al., 2014). However, some evidence casts doubt on mind-wandering as an exclusively negative state. Indeed, mind-wandering can have a positive impact, for example, when one is planning the future or looking for creative solutions (Baird et al. 2012; Zedelius \& Schooler, 2016; see Smallwood \& Schooler, 2013, for a review of the costs and benefits of mind-wandering). Similarly, recent conceptualizations of boredom suggest that boredom is neither good nor bad per se, but simply signals that one should deploy one's attentional 
resources elsewhere (Danckert, 2019; Westgate \& Wilson, 2018; Wolff \& Martarelli, 2020). Indeed, research shows that boredom is a motivator of adaptive and maladaptive behaviors alike (Westgate \& Wilson, 2018).

In light of the apparent similarities between boredom and mind-wandering, the relationship (and potential overlap) between the two constructs is of interest. In 1926, Davies already suggested that mind-wandering occurs when one is experiencing boredom. Following from the proposition that boredom is a signal that one should explore behavioral alternatives (Danckert, 2019; Geana et al., 2016), this is plausible: When one is stuck in a situation in which no rewarding behavioral alternative is available, one option is to shift attention away from the task and explore inner worlds which are always available and thereby can reduce boredom (Mills \& Christoff, 2018).

In summary, boredom and mind-wandering play a large and frequent role in everyday life, but research on interconnections between the two concepts is still relatively scarce. There is a need for understanding the interplay between mind-wandering and boredom in everyday life (e.g., in a classroom or at the workplace) and in experimental settings (e.g., undemanding tasks). To advance research on mind-wandering and boredom, the present paper aims to a) provide a German translation of two frequently used self-report scales for boredom and mindwandering and $b$ ) investigate the combined latent structure of the two concepts.

\section{Part 1: German translation and validation of mind-wandering and boredom scales}

Our first goal was to provide a German translation of two frequently used self-report scales for the assessment of trait boredom and mind-wandering and to test the psychometric properties of these scales. We chose the Spontaneous and Deliberate Mind-Wandering Scales (SDMWS; Carriere, Seli, \& Smilek, 2013) and the Short Boredom Proneness Scale (SBPS; Struk, Carriere, Cheyne, \& Danckert, 2017), as both have been shown to be reliable and valid measures of mind-wandering and boredom proneness (Chiorri \& Vanucci, 2019; Isacescu et al., 2017, Marcusson-Clavertz \& Kjell, 2019; Struk et al., 2017; Vanucci \& Chiorri, 2018). 
Empirical evidence supports a two-dimensional conceptualization of mind-wandering that differentiates between spontaneous and deliberate mind-wandering (Marcusson-Clavertz \& Kjell, 2019; see also Carriere et al., 2013; Chiorri \& Vannucci, 2019). Spontaneous mindwandering is characterized by an uncontrolled shift of attention away from a primary task (e.g., "I mind wander even when I'm supposed to be doing something else"), whereas deliberate mind-wandering is characterized by an intentional shift of attention away from the primary task (e.g., "I allow my thoughts to wander on purpose"). Building on the differentiation between spontaneous and deliberate mind-wandering, Marcusson-Clavertz and Kjell (2019) focused on associations with these dimensions and showed that spontaneous mind-wandering was strongly positively correlated with poor attentional control (as measured by the Short Imaginal Processes Inventory, SIPI; Huba, Singer, Aneshensel, \& Antrobus, 1982) and predicted generalized anxiety disorder (as measured by the Generalized Anxiety Disorder Scale-7, GAD-7; Spitzer, Kroenke, Williams, \& Löwe, 2006), whereas deliberate mind-wandering was moderately positively correlated with positive-constructive daydreaming (SIPI, Huba et al., 1982) and predicted the Big-Five trait openness to experience. In another study, these authors investigated whether spontaneous and/or deliberate mind-wandering were specific at predicting the occurrence of actual episodes of spontaneous and/or deliberate mind-wandering (experience-sampling reports during a task with three options, namely, ontask, spontaneous mind-wandering, deliberate mind-wandering). Their results provided further evidence of convergent and discriminant validity. Specifically, they showed that spontaneous mind-wandering (trait) predicted the occurrence of spontaneous, but not deliberate mind-wandering during the task. Similarly, deliberate mind-wandering (trait) predicted deliberate, but not spontaneous mind-wandering during the task. In agreement with Seli, Risko, and Smilek (2016), the authors highlight the relevance of considering both facets of mind-wandering to understand when mind-wandering occurs. 
In regard to boredom, Struk and colleagues (2017) assessed the factor structure and validity of two commonly used measures of trait boredom: the Boredom Proneness Scale (BPS; Farmer \& Sundberg, 1986) and the Boredom Proneness Scale-Short Form (BPS-SR; Vodanovich, Wallace, \& Kass, 2005). In their study, Struk and colleagues showed that the inconsistencies in the results of previous factor analyses of the BPS can be explained by the use of reverse-coded items. So, they proposed and validated the SBPS, which is a onefactorial measure of eight consistently worded items (see also Isacescu \& Danckert, 2018; Isacescu et al., 2017). This newly developed scale exhibited good internal consistency and construct validity. Trait boredom as measured by the SBPS was positively correlated with aggression (Aggression Questionnaire, AQ; Buss \& Perry, 1992), depression, anxiety, and stress (Short Form Depression Anxiety Stress Scale, DASS-21; Lovibond \& Lovibond, 1995), ADHD symptoms (ADHD Self-Report Scale Screener, ASRS-Screener; Kessler et al., 2005), spontaneous mind-wandering (SMW; Carriere et al., 2013), and with lapses of attention (Five-Facet Mindfulness Questionnaire-acting with awareness subscale, FFMQ-A; Baer, Smith, Hopkins, Krietemeyer, \& Toney, 2006).

In view of the need for short measures that reliably assess mind-wandering and boredom in different contexts, we translated the SDMWS and the SBPS into German. Because of the increased interest in these constructs in experimental, clinical, and educational psychology, we believe that a German version of these scales would be a valuable addition to the existing scales. As for the two constructs' latent structure, we expected to replicate a twofactorial model for the SDMWS (spontaneous and deliberate mind-wandering) and a onefactorial model for the SBPS. We then tested convergent and divergent validity by assessing correlations with related and unrelated psychological constructs. For validation, we additionally assessed the open-mindedness dimension of the Big Five Personality Inventory. Contrary to boredom, which involves a host of negative emotions (e.g., lack of control: Mugon, Struk, \& Danckert, 2018; anxiety: Sommers, \& Vodanovich, 2000; depression: 
Goldberg, Eastwood, LaGuardia, \& Danckert, 2011; anger: Dahlen, Martin, Ragan, \& Kuhlman, 2004), open-mindedness has a positive connotation and is characterized by receptivity to an inner world of imagination and an active, creative fantasy life (Costa \& McCrae, 1992). Because open-mindedness is associated with constructive mind-wandering and has an inherent intentional component, we predict that open-mindedness is differentially related to spontaneous and deliberate mind-wandering (Marcusson-Clavertz \& Kjell, 2019; Weibel, Martarelli, Häberli, \& Mast, 2018; Zedelius \& Schooler, 2016; Zhiyan \& Singer, 1996).

In summary, higher levels of boredom proneness have been shown to be associated with the occurrence of spontaneous mind-wandering and to a much lesser extent with the occurrence of deliberate mind-wandering (Isacescu et al., 2017). Moreover, openness to experience appears to be negatively related to boredom (Culp, 2006) and positively related to deliberate mind-wandering (Marcusson-Clavertz \& Kjell, 2019). We expected to find similar correlations between the constructs under investigation in the present study. We believe that this concurrent validation of the German version of the scales will be an important step in addressing the similarities and differences between boredom and the two facets of mindwandering.

Part 2: A psychometric network approach to the relationship between boredom and the facets of mind-wandering

Our second goal was to explore the proposed relationship between boredom and different facets of mind-wandering (e.g., Danckert \& Merrifield, 2018; Isacescu et al., 2017; Struk et al., 2017). To assess whether boredom, spontaneous mind-wandering, and deliberate mind-wandering represent three separate latent dimensions, we employed exploratory graph analysis (EGA), a recently developed technique from the field of network psychometrics (Golino \& Epskam, 2017). Network psychometrics has increased in popularity in recent years and approaches from network psychometrics have been applied to diverse fields of 
psychological research (Golino \& Demetriou, 2017). Network psychometrics is an exploratory data-driven approach that allows one to estimate unique relationships between items that remain after controlling for all other items in the network (Christensen, Golino, \& Silvia, 2019; Fried \& Cramer, 2017). In this approach, items are considered to directly affect each other rather than being caused by an unobserved latent construct. Within the network, items that share strong connections and are in close proximity to each other can form any number of communities. This provides insight into the interrelationships between all items that comprise the SDMWS and SBPS and allows us to assess which items are grouped together in a network community. While there is some evidence for causal relationships between boredom and mind-wandering in the literature (Eastwood et al., 2012), our approach takes a step back by not positing causal relationships between the observed items, but rather focusing on identifying the network structure that reflects both constructs. We believe this approach is an important first step before we specify the underlying mechanisms through which variables influence each other. Thus, in the present paper, we will assess how many communities in the network structure the SBPS and SDMWS items form and which items belong to which dimension. We believe this approach is better suited to this more explorative research question and might greatly enhance our understanding of the relationship between boredom and mind-wandering.

\section{Method}

The questionnaires were translated into German through a forward- and backtranslation procedure. In a first step, the questionnaires were translated into German by two independent translators. Discrepancies were discussed by the two translators and the authors of this paper. The newly developed German versions were then translated back into English by an independent translator (bilingual). The translators had no knowledge of the underlying constructs. Discrepancies were again discussed in the panel of experts. The final version of the translated items (as well as the original English version) are shown in Table 1. 
Insert Table 1 about here

To establish the factor structure of the newly translated scales, data of a Germanspeaking convenience sample were collected online via social media (link distributed via Facebook, online community groups, advertisement in an internal university publication, etc.). To assess cross-cultural robustness, we analyzed data obtained using the original versions of the SDMWS and SBPS from an additional US sample. The English-speaking sample was recruited from Amazon's website Mechanical Turk. Participants completed the questionnaires online, using the freely available open source software Limesurvey (www.limesurvey.org). The local ethics committee approved the study, which was conducted in accordance with the Declaration of Helsinki.

\section{Procedure}

After giving informed consent, the participants in the two samples reported their age, gender, employment, country of residence, and country of origin. In addition, they confirmed that they were at least 18 years of age and that they understand written German / English well.

In the English-speaking sample, only the SDMWS and SBPS were assessed. To detect participants that failed to follow instructions and thus to improve data quality, we included two instructional manipulation check (IMC) items, one in each questionnaire (Oppenheimer, Meyvis, \& Davidenko, 2009). The two questionnaires were presented in counterbalanced order.

In the German-speaking sample, after presenting the SDMWS and SBPS in counterbalanced order, we additionally included the open-mindedness scale (BFI-2-S; 6 items), the Mannheim dream questionnaire (MADRE; Schredl, Berres, Klingauf, Schellhaas, \& Göritz, 2014; 10 items), and selected items from the Lucid Dreaming Skills Questionnaire (LUSK; Schredl, Rieger, \& Göritz, 2018) in fixed order (first open-mindedness scale, 
followed by MADRE and LUSK). The data obtained from the MADRE and LUSK were not considered in the context of this study. Details about the sample and the materials are reported below.

\section{Participants}

We aimed to test at least 600 participants (300 per sample). A recent simulation study by Kretzschmar and Gignac (2019) showed that an $N$ of 490 is needed to achieve stable estimation when it comes to latent variable correlations. In the following, we report how data were excluded, as well as all manipulations, and all measures assessed in the study. The R code to reproduce analyses as well as the data set is available on OSF (https://osf.io/tg3fq/).

German-speaking convenience sample. Of the 498 participants, 439 completed the online questionnaire with no particular incentive given. 21 participants $(4.8 \%)$ did not answer at least one of the two IMC items correctly and where thus excluded from further analyses. Ten of the remaining 418 participants $(78.47 \%$ female) only completed one of the two questionnaires (only SDMWS or SBPS). Six additional participants did not complete the open-mindedness scale. These participants were not excluded from analyses of data separated by questionnaire. However, they were excluded from analyses of the full dataset (listwise deletion). The participants' average age was 33.13 years $(S D=10.82)$. Their occupations were classified as student (29.67\%), service sector (27.75\%), academic profession (16.27\%), social services $(11.00 \%)$, technician $(8.14 \%)$, executive $(2.39 \%)$, sales $(1.20 \%)$, temporary staff $(0.72 \%)$, and other $(2.15 \%)$. The participants were mainly residents of Switzerland (60.05\%), followed by Germany (35.89\%).

English-speaking MTurk sample. Of the 686 participants, 635 completed the online questionnaire for $\$ 0.50$ USD. When the same participants took part in the survey more than once, the duplicates were removed and only the first participation was included in the final dataset $(N=569)$. Seventy-three participants $(12.83 \%)$ did not answer at least one of the two IMC items correctly and were thus excluded from further analyses. The remaining sample (we 
had no missing values in this sample) was constituted of 496 participants ( $41.53 \%$ female) with an average age of 32.64 years $(S D=9.78)$. Their occupations were classified as technician (20.97\%), sales (17.34\%), service sector (14.72\%), executive (8.27\%), academic profession $(7.66 \%)$, student $(4.03 \%)$, agriculture $(2.62 \%)$, temporary staff $(2.62 \%)$, social services $(2.22 \%)$, and other $(19.56 \%)$. The majority were residents of the United States (73.39\%), followed by India (23.39\%). As the SBPS and the SDMWS are validated and used with US and English-speaking Canadian samples, participants who indicated that they were not from Canada or the US where excluded from further analyses. The US sample consisted of 364 participants $(45.33 \%$ female $)$.

\section{Materials}

Spontaneous and Deliberate Mind-Wandering Scales (SDMWS; Carriere et al., 2013). We used the SDMWS (see Table 1), which were recently validated by Marcusson-Clavertz and Kjell (2019) as well as by Vannucci and Chiorri (2018). It is a short tool used to investigate deliberate mind-wandering (4 items, e.g., "I allow my thoughts to wander on purpose") and spontaneous mind-wandering (4 items, e.g., "I find my thoughts wandering spontaneously"). The mean response scores for the two dimensions were computed.

Boredom Proneness Scale-Short Form (SBPS; Struk et al., 2017). We used the SBPS, which is a short tool used to investigate boredom ( 8 items, e.g., "I often find myself at 'loose ends,' not knowing what to do"). The mean response score for the one dimension was computed (see Table 1 for the scale with answers).

Open-Mindedness Scale (BFI-2-S; Soto \& John, 2017; Danner et al., 2016; Rammstedt, Danner, Soto, \& John, 2018). In the German-speaking sample, we also administered the open-mindedness scale. It consists of 6 items (e.g., "I am someone who is inventive, finds clever ways to do things") rated on a 5-point Likert scale ranging from strongly disagree to strongly agree. 
Instructional manipulation check items (IMC; Oppenheimer et al., 2009). Two IMC items (e.g., "It is very important that you are focused while filling out this survey. Please check Option 7 (strongly agree)") were included to detect participants that failed to follow instructions and thus to reduce noise, to increase the validity of the data and statistical power.

\section{Statistical approach}

To assess our first research question, we used a confirmatory approach. For internal consistency of the scales, we computed Cronbach's alpha, McDonald's omega, and the composite reliability score. In contrast to Cronbach's alpha, omega and the composite reliability score do not assume essentially tau-equivalent items, but allow different factor loadings of items on the common factor (for McDonald's omega, see Dunn, Baguley, \& Brunsden, 2014; for the composite reliability score, see Raykov, 1997, 2004).

The confirmatory factor analyses (CFAs) and the measurement invariance analyses were computed with jamovi (The jamovi project, 2019) and $R$ (R core Team, 2018). We used the lavaan (Rossel, 2018) and psych packages (Revelle, 2019) to run the models. Maximum likelihood estimates were employed. To identify the models, factor variances were constrained to one. To evaluate model fit, the following measures were retained: comparative fit index (CFI) above .95 for a good fit, standardized root square mean residual (SRMR) below .08 for a good fit, root mean square error of approximation (RMSEA) below .05 for a good fit, and Tucker-Lewis Index (TLI) above .90 for an acceptable fit and above .95 for a good fit.

To evaluate measurement invariance across samples, we tested five models with increasingly restrictive specifications across samples (based on the following questions: is the factor structure the same? are the factor loadings the same? are the intercepts the same? are the residual variances the same? are the means the same?). We compared the models using a cutoff value of .01 for the difference of CFI to indicate non-invariance, paired with changes in RMSEA of .015 (Chen, 2007). 
To assess our second research question, we used EGA to analyze the psychometric network that is spanned by the mind-wandering and boredom items and to see how many communities could be identified. This part of the analysis was also done using $R$ ( $\mathrm{R}$ core Team, 2018) with the functionality of the EGAnet package (Golino \& Christensen, 2019). For this analysis, we combined the US sample and the German sample. We chose EGA because this approach has outperformed other methods (e.g., parallel analysis or Kaiser-Guttman's rule) especially when it comes to the estimation of structures with more than two factors (for an in-depth description of EGA, see Golino \& Epskam, 2017). Most importantly, interconnections on an item level can be standardized and visualized, thus fitting perfectly with our goal of investigating the interplay between the different constructs. To avoid spurious correlations, EGA utilizes the least absolute shrinkage and selection operator with the regularization parameter specified using extended Bayesian information criterion and the number of dimensions is estimated using the walktrap algorithm (Golino \& Epskam, 2017).

\section{Results - Part 1: Confirmatory approach}

The internal consistency of the scales and descriptive statistics are reported in Table 2. The newly translated scales showed high internal consistency; skewness and kurtosis were low.

Insert Table 2 about here

\section{Two-factorial model of mind-wandering}

CFA in the German-speaking sample. To test whether the two-factorial model fit the data, we computed a CFA. The model fit indexes ranged from acceptable to good, $\chi 2(19)=$ $66.70, p<.001 ; \mathrm{CFI}=.951, \mathrm{TLI}=.928, \mathrm{SRMR}=.062, \mathrm{RMSEA}=.078(90 \% \mathrm{CI}=.058-$ 0.098). Furthermore, all factor loadings were significant $(p<.001)$ and the two factors were correlated $(r=0.309, p<.001)$. Factor loadings including confidence intervals are reported in 
Table 3. To assess whether the two-factorial model is superior to a more parsimonious solution in accounting for the observed data, an additional one-factorial model was tested (see Appendix A for results). The two-factorial model showed a substantially better fit than the one-factorial model.

Insert Table 3 about here

CFA in the US sample. The model fit indexes ranged from acceptable to good, $\chi 2(19)$ $=55.15, p<.001 ; \mathrm{CFI}=.976, \mathrm{TLI}=.964, \mathrm{SRMR}=.050, \mathrm{RMSEA}=.072(90 \% \mathrm{CI}=.050-$ 0.095). All factor loadings were significant $(p<.001)$ and the two factors were correlated $(r=$ $0.716, p<.001)$. Factor loadings including confidence intervals are reported in Table 3. To assess whether the two-factorial model is superior to a more parsimonious solution in accounting for the observed data, an additional one-factorial model was tested (see Appendix A for results). The two-factorial model showed a substantially better fit than the one-factorial model.

Measurement invariance across samples. The SDMWS demonstrated weak measurement invariance. Changes in CFI are reported in Table 4 and support an invariant factor structure and invariant factor loadings, but not invariant item intercepts, residual variance, or factor means (see Table 4).

Insert Table 4 about here

\section{One-factorial model of boredom}

CFA in the German-speaking sample. To test whether the one-factorial model fits the data, we computed a CFA. The model fit indexes ranged from acceptable to good, $\chi 2(20)=$ 
$100.27, p<.001 ; \mathrm{CFI}=.935, \mathrm{TLI}=.910, \mathrm{SRMR}=0.044, \mathrm{RMSEA}=.099(90 \% \mathrm{CI}=.080-$ 0.119). All factor loadings were significant (see Table 5).

CFA in the US sample. The model fit indexes ranged from acceptable to good, $\chi 2(20)=$ $76.15, p<.001 ; \mathrm{CFI}=.970, \mathrm{TLI}=.957, \mathrm{SRMR}=0.033, \mathrm{RMSEA}=.088(90 \% \mathrm{CI}=.067-$ 0.109). Furthermore, all factor loadings were significant (see Table 5).

Measurement invariance across samples. The SBPS demonstrated weak measurement invariance. Changes in CFI are reported in Table 5 and support an invariant factor structure and invariant factor loadings, but not invariant item intercepts, residual variance, or factor means.

Insert Table 5 about here

\section{Evidence of construct validity}

We analyzed the relationship between the two facets of mind-wandering, boredom, and open-mindedness. Deliberate mind-wandering and spontaneous mind-wandering were weakly correlated in the German-speaking sample and strongly correlated in the US sample. In both samples, deliberate mind-wandering was weakly correlated with boredom, whereas spontaneous mind-wandering was strongly associated with boredom. It is interesting to note that open-mindedness was weakly correlated with deliberate mind-wandering (convergent validity), not correlated with spontaneous mind-wandering (divergent validity), and negatively correlated with boredom (convergent validity). The correlations are reported in Table 6.

Insert Table 6 about here

\section{Results - Part 2: Exploratory approach}


The EGA yielded a psychometric network with three distinct communities. All items of the SBPS were associated with one boredom dimension, all four items of the spontaneous mind-wandering subscale formed a spontaneous mind-wandering dimension, and the deliberate mind-wandering items were all associated with a deliberate mind-wandering dimension.

Insert Figure 1 about here

Figure 1 represents the identified psychometric network and shows how the items are interconnected in the whole sample. The network has 16 nodes and 74 non-zero edges out of 120. The structure is parsimonious (compare network of correlations and network of partial correlations reported in Appendix B for descriptive purposes) due to the Extended Bayesian Information Criterion Graphical Least Absolute Shrinkage and Selection Operator (EBICglasso), which estimates partial correlations between all variables and shrinks the absolute weights to zero (Epskamp, Cramer, Waldorp, Schmittmann, \& Borsboom, 2012; Friedman, Hastie, \& Tibshirani, 2008). In network analysis, the nodes represent the items and the edges represent conditional dependence between the items. The closer the nodes, the more likely they belong to the same facet and a node's color indicates clustering as identified by the walktrap algorithm. The network analysis identified the three psychometrically distinct dimensions of deliberate mind-wandering, spontaneous mind-wandering, and boredom ${ }^{1}$. The edge colors connecting the items indicate the direction of the relationship (blue representing positive and red representing negative) and the thickness of an edge reflects the strength of relationship. Strong positive connections emerged between all items belonging to the same

\footnotetext{
${ }^{1}$ Here we used an approach that deterministically assigns nodes to a community (walktrap communities). However, there are other approaches that allow nodes to belong to different communities (e.g., clique percolation, see Fried, 2019). When following such an approach (analysis not included in the paper, see https://osf.io/tg3fq/ for supplementary information), the three communities clearly emerged again (each item only belonging to its community).
} 
facet and sparse connections emerged between items belonging to different facets. Visual inspection revealed connections between SMW1 ("I find my thoughts wandering spontaneously") and DMW2 ("I enjoy mind-wandering"), between SMW2 ("When I mindwander my thoughts tend to be pulled from topic to topic") and DMW4 ("I allow myself to get absorbed in pleasant fantasy"), and SBPS1 (“I often find myself at 'loose ends,' not knowing what to do"), and SMW4 ("I mind wander even when I'm supposed to be doing something else").

Insert Figure 2 about here

The importance of individual nodes in the network can be assessed by computing node centrality measures (Epskamp, Borsboom, Fried, 2016; Opsahl, Agneessens, \& Skvoretz, 2010). The results of the visual analysis of centrality can be seen in Figure 2. The values of betweenness are relatively high for SMW4 and SBPS1, which means that there are more shortest paths that pass through those items compared to the others. The closeness measure (the inverse of the sum of all shortest paths from the node of interest to all other nodes) shows a similar picture. The strength measure (sum of absolute input weights of a node) additionally identifies the items DMW2 and SBPS6. Overall, higher centrality measures indicate that the node is more central to the network. The weights of the estimated network are reported in Appendix C. For a visualization of the nomological network and its relationship to openmindedness, see Appendix D.

\section{Discussion}

In this article, we report the translation into German and validation of two self-report measures of mind-wandering and boredom (SDMWS; Carriere et al., 2013; SBPS; Struk et al., 2017). The CFAs confirmed the factor structure for both constructs (two-factorial solution for the SDMWS and one-factorial solution for SBPS). There is growing empirical research 
highlighting the importance of distinguishing between deliberate and spontaneous mindwandering on a trait level (e.g., Seli, Carriere, \& Smilek, 2015). Our results offer additional support for the validity of this distinction and the unique correlates of these dimensions.

Even though the factor structure replicated across German-speaking and Englishspeaking samples, we also observed some differences, for example, with respect to the overlap between spontaneous mind-wandering and deliberate mind-wandering. A moderate overlap was observed in the German-speaking sample $(r=0.31)$, whereas a large overlap was observed in the English-speaking sample $(r=0.72)$. Participants in the two samples were administered the same online questionnaire (same format of presentation, same text, etc.). The differences were 1) the language and 2) the type of sample (convenience sample vs. paid sample). We think that the differences found can be explained by the type of sample used (convenience vs. paid sample) rather than by the language. For example, Marcusson-Clavertz and Kjell (2019) used MTurk samples and also found a high correlation between the two factors ( $r=0.62$ in the first study and $r=0.67$ in the second study), whereas Chiorri and Vannucci (2019), who used unpaid samples, found less overlap between the two dimensions $(r=0.43$ in a paper and pencil sample and $r=0.27$ in an online sample). In general, we observed higher correlations in the MTurk sample. The high correlations observed in the MTurk sample point out a possible concern with MTurk participants showing less variance in their responses (participants giving similar responses across all items). This might also explain why our two samples showed invariant factor structure and factor loadings, but not invariant item intercepts, residual variance, or factor means. However, we clearly replicated the factor structures in the MTurk sample as well, thus rather suggesting that this method of data collection is valid. These platforms are simple to use and can recruit large samples of participants in a fast manner and at low cost, and thus allow researchers to carry out highpowered online studies. 
On a state level, both mind-wandering and boredom are associated with impaired performance in a primary task (e.g., Stawarczyk, Majerus, Maj, Van der Linden, \& D’Argembeau, 2011, for mind-wandering; Milyavskaya, Inzlicht, Johnson, \& Larson, 2019, for boredom), negative emotions (e.g., Killingsworth \& Gilbert, 2010, for mind-wandering; Sommers, \& Vodanovich, 2000, for boredom), and activation in specific brain areas (i.e., default mode network, e.g., Spreng, Mar, \& Kim, 2009, for mind-wandering, Danckert \& Merrifield, 2018, for boredom). On a trait level, it has been shown that there is a positive relationship between spontaneous mind-wandering and boredom $(r=.43$, in Struk et al., 2017). Here, we replicate this finding and extend it by illustrating that the association between deliberate mind-wandering and boredom is substantially weaker (consistent with the findings of Isacescu et al., 2017). Using hierarchical regression analysis, Isacescu et al. (2017) showed that spontaneous mind-wandering (and not deliberate mind-wandering) was a significant positive predictor of boredom proneness. These distinctive associations between boredom, spontaneous mind-wandering, and deliberate mind-wandering lend support to a selfregulatory explanation of boredom (Isacescu et al., 2017). Deliberate mind-wandering might work as a self-control strategy that can be used to counteract boredom. For example, Weibel et al. (2018) found that participants with higher levels of fantasy reported feeling less bored when forced to wait 8 minutes (Study 6c). It seems that participants with higher levels of fantasy become more easily immersed in inner worlds and thus feel less bored when there is nothing else to do (Weibel et al., 2018). Deliberate mind-wandering was weakly correlated with open-mindedness (consistent with the findings of Marcusson-Clavertz \& Kjell, 2019) thus further suggesting that deliberate mind-wandering is a special form of mind-wandering essentially flexible and creative in kind. Indeed, mind-wandering may not purely be a failure of our cognitive system, but it may be beneficial when it comes to creativity or autobiographical thoughts and future-oriented planning (Mooneyham \& Schooler, 2013). It is possible that the origin of the cost vs. benefit inconsistencies of mind-wandering can be 
explained by the conflation of spontaneous and deliberate mind-wandering in empirical research (Seli, Carriere, \& Smilek, 2015).

Importantly, the EGA clearly revealed the three distinctive dimensions of spontaneous mind-wandering, deliberate mind-wandering, and boredom. Items were placed in the network according to the presumed underlying dimension (all boredom items were placed within the boredom dimension, etc.). Thus, although the constructs are correlated, they appear to reflect distinct dimensions. For example, the affective valence of the three dimensions is likely different since boredom is conceptualized as a negative affective state (Sommers \& Vodanovich, 2000), while it is less clear how mind-wandering is conceptualized (Mooneyham $\&$ Schooler, 2013). This might also explain some of the difficulties in boredom research that stem from the challenge of getting a participant bored by a boring task. Indeed, not all participants get bored when they carry out a boring task and it has been proposed that individual differences in mind-wandering might play a role (Mills \& Christoff, 2018). If a boring task does not require constant cognitive engagement, then participants can engage in deliberate mind-wandering and research shows that participants differ in the valence they ascribe to being left mind-wandering (Fox, Thompson, Andrews-Hanna, \& Christoff, 2014; Wilson et al., 2014). In the same vein, the concepts might also be characterized by different levels of individual agency: While the sensation of boredom is frequently accompanied by a perceived lack of agency (Raffaelli, Mills, \& Christoff, 2018), mind-wandering (especially deliberate mind-wandering) does not necessarily imply a lack of agency in one's current behavior. Although boredom and both facets of mind-wandering might vary with respect to the affective valence they induce and the agency that is associated with them, they are all linked with disengagement from assigned activities. Simply put, boredom and mindwandering both seem to indicate that a current task is not worth one's full attention. Our results emphasize the need to investigate these constructs as multifaceted states in which 
people have different approaches and capacities to deal with a task that is not worth their full attention.

Some limitations of the study should be considered when interpreting the findings. A larger number of samples should be tested to compare measurement invariance across not only samples speaking different languages, but also for example across type of sample (convenience sample, undergraduate student sample, paid sample, MTurk sample, etc.). Future research would benefit from examining the generalizability in more detail using other samples, especially because our test of measurement invariance across samples only partially holds. Further, this study is based on trait self-report measures. It would be important to integrate these measures with online experience-sampling methods (i.e., state boredom, state spontaneous mind-wandering, state deliberate mind-wandering) and neurophysiological measures (e.g., pupil dilation) to better understand the differences between the constructs under investigation (for a similar proposition to place emphasis on psychoneurophysiological approaches that allow to capture the temporal dynamics of the constructs of interest, see Wolff \& Martarelli, 2020). In conclusion, the present research provides an important contribution by introducing the German version of the SDMWS and SBPS. Our findings indicate that the scales are valid measures of boredom and facets of mind-wandering that may benefit future research and be useful in understanding the nature of the constructs and their interactions.

\section{References}

Baer, R. A., Smith, G. T., Hopkins, J., Krietemeyer, J., \& Toney, L. (2006). Using self-report assessment methods to explore facets of mindfulness. Assessment, 13(1), 27-45. doi:10.1177/1073191105283504

Baird, B., Smallwood, J., Mrazek, M. D., Jam, J. W., Franklin, M. S., \& Schooler, J. W. (2012). Inspired by distraction: Mind-wandering facilitates creative incubation. Psychological Science, 23(10), 1119-1122. doi:10.1177/095679761244 6024 
Bench, S. W., \& Lench, H. C. (2013). On the function of boredom. Behavioral Sciences, 3(3), 459-472. doi:10.3390/bs3030459

Bench, S. W., \& Lench, H. C. (2019). Boredom as a seeking state: Boredom prompts the pursuit of novel (even negative) experiences. Emotion, 19(2), 242-254. doi:10.1037/emo0000433

Buss, A. H., \& Perry, M. (1992). The aggression questionnaire. Journal of Personality and Social Psychology, 63(3), 452-459. doi:10.1037/0022-3514.63.3.452

Carriere, J. S. A., Seli, P., \& Smilek, D. (2013). Wandering in both mind and body: Individual differences in mind-wandering and inattention predict fidgeting. Canadian Journal of Experimental Psychology, 67(1), 19-31. doi:10.1037/a0031438

Chen, F. F. (2007). Sensitivity of goodness of fit indexes to lack of measurement invariance. Structural Equation Modeling, 14(3), 464-504. doi:10.1080/10705510701301834

Chiorri, C., \& Vannucci, M. (2019). Replicability of the psychometric properties of traitlevels measures of spontaneous and deliberate mind-wandering. European Journal of Psychological Assessment, 35(4), 459-468. doi:10.1027/1015-5759/a000422

Christensen, A. P., Golino, H., \& Silvia, P. J. (2019). A psychometric network perspective on the measurement and assessment of personality traits. doi:10.31234/osf.io/ktejp

Christoff, K., Mills, C., Andrews-Hanna, J. R., Irving, Z. C., Thompson, E., Fox, K. C. R., \& Kam, J. W. Y. (2018). Mind-wandering as a scientific concept: Cutting through the definitional haze. Trends in Cognitive Sciences, 22(11), 957-959.

doi:10.1016/j.tics.2018.07.004

Costa, P., \& McCrae, R. R. (1992). NEO PI-R: Revised NEO Personality Inventory (NEO PI-R). Odessa, FL: Psychological Assessment Resources.

Culp, N. A. (2006). The relations of two facets of boredom proneness with the major dimensions of personality. Personality and Individual Differences, 41(6), 999-1007. doi:10.1016/j.paid.2006.02.018 
Dahlen, E. R., Martin, R. C., Ragan, K., \& Kuhlman, M. M. (2004). Boredom proneness in anger and aggression: Effects of impulsiveness and sensation seeking. Personality and Individual Differences, 37(8), 1615-1627. doi:10.1016/j.paid.2004.02.016

Danckert, J. (2019). Boredom: Managing the delicate balance between exploration and exploitation. In J. Ros Velasco (Ed.), Boredom is in your mind: A shared psychological philosophical approach (Vol. 2, pp. 37-53). Cham, Switzerland: Springer. doi:10.1007/978-3-030-26395-9_3

Danckert, J., \& Merrifield, C. (2018). Boredom, sustained attention and the default mode network. Experimental Brain Research, 236(9), 2507-2518. doi:10.1007/s00221-016$4617-5$

Danner, D., Rammstedt, B., Bluemke, M., Treiber, L., Berres, S., Soto, C., \& John, O. (2016). Die deutsche Version des Big Five Inventory 2 (BFI-2). Die Zusammenstellung Sozialwissenschaftlicher Items Und Skalen. doi:10.6102/zis247

Davies, A. H. (1926). Discussion on the physical and mental effects of monotony in modern industry. British Medical Journal, 2(3427), 472-479.

Dunn, T. J., Baguley, T., \& Brunsden, V. (2014). From alpha to omega: A practical solution to the pervasive problem of internal consistency estimation. British Journal of Psychology, 105(3), 399-412. doi:10.1111/bjop.12046

Eastwood, J. D., Frischen, A., Fenske, M. J., \& Smilek, D. (2012). The unengaged mind: Defining boredom in terms of attention. Perspectives on Psychological Science, 7(5), 482495. doi:10.1177/1745691612456044

Epskamp, S., Borsboom, D., \& Fried, E. I. (2016). Estimating psychological networks and their accuracy: A tutorial paper. arXiv preprint, arXiv:1604.08462.

Epskamp, S., Cramer, A., Waldorp, L., Schmittmann, V. D., \& Borsboom, D. (2012). qgraph: Network visualizations of relationships in psychometric data. Journal of Statistical Software, 48(1), 1-18. doi:10.18637/jss.v048.i04 
Epskamp, S., Maris, G., Waldorp, L. J., \& Borsboom, D. (2015). Network psychometrics: Handbook of psychometrics. New York, NY: Wiley.

Farmer, R., \& Sundberg, N. D. (1986). Boredom proneness: The development and correlates of a new scale. Journal of Personality Assessment, 50(1), 4-17. doi:10.1207/s15327752jpa5001_2

Fox, K. C., Thompson, E., Andrews-Hanna, J. R., \& Christoff, K. (2014). Is thinking really aversive? A commentary on Wilson et al.'s "Just think: the challenges of the disengaged mind.” Frontiers in Psychology, 5:1427. doi:10.3389/fpsyg.2014.01427

Fried, E. (2019). R tutorial. Clique percolation to detect communities in networks. https://psych-networks.com/r-tutorial-clique-percolation-to-detect-communities-innetworks/

Fried, E. I., \& Cramer, A. O. J. (2017) Moving forward: Challenges and directions for psychopathological network theory and methodology. Perspectives on Psychological Science, 12(6), 999-1020. doi:10.1177/1745691617705892

Friedman, J. H., Hastie, T., \& Tibshirani, R. (2008). Sparse inverse covariance estimation with the graphical lasso. Biostatistics, 9(3), 432-441. doi:10.1093/biostatistics/kxm045.

Geana, A., Wilson, R., Daw, N. D., \& Cohen, J. (2016). Boredom, information-seeking and exploration. In Proceedings of the Annual Conference of the Cognitive Science Society.

Giambra, L. M. (1995). A laboratory method for investigating influences on switching attention to task-unrelated imagery and thought. Consciousness and Cognition, 4(1), 1-21. doi:10.1006/cog.1995.1001.

Goldberg, Y. K., Eastwood, J. D., LaGuardia, J., \& Danckert, J. (2011). Boredom: An emotional experience distinct from apa- thy, anhedonia, or depression. Journal of Social \& Clinical Psychology, 30(6), 647-666. doi:10.1521/jscp.2011.30.6.647 
Golino, H. F., \& Christensen, A. P. (2019). EGAnet: Exploratory Graph Analysis - A framework for estimating the number of dimensions in multivariate data using network psychometrics. R package version 0.6.0.

Golino, H. F., \& Demetriou, A. (2017). Estimating the dimensionality of intelligence like data using Exploratory Graph Analysis. Intelligence, 62(C), 54-70.

doi:10.1016/j.intell.2017.02.007

Golino H. F., \& Epskamp S. (2017). Exploratory graph analysis: A new approach for estimating the number of dimensions in psychological research. PLoS ONE 12(6): e0174035. doi: 10.1371/journal.pone.0174035

Gomez-Ramirez, J., \& Costa, T. (2017). Boredom begets creativity: A solution to the exploitation-exploration trade-off in predictive coding. Bio Systems, 162, 168-176. doi:10.1016/j.biosystems.2017.04.006

Götz, T., Frenzel, A. C., Hall, N. C., Nett, U. E., Pekrun, R., \& Lipnevich, A. A. (2014). Types of boredom: An experience sampling approach. Motivation and Emotion, 38(3), 401-419. doi:10.1007/s11031-013-9385-y

Huba, G. J., Singer, J. L., Aneshensel, C. S., \& Antrobus, J. S. (1982). The Short Imaginal Processes Inventory. Port Hurson, MI: Research Psychologists Press.

Isacescu, J., \& Danckert, J. (2018). Exploring the relationship between boredom proneness and self-control in traumatic brain injury (TBI). Experimental Brain Research, 236(9), 2493-2505. doi:10.1007/s00221-016-4674-9

Isacescu, J., Struk, A. A., \& Danckert, J. (2017). Cognitive and affective predictors of boredom proneness. Cognition and Emotion, 31(8), 1741-1748. doi:10.1080/02699931.2016.1259995

Kessler, R. C., Adler, L., Ames, M., Demler, O., Faraone, S., Hiripi, E. V. A., . . Walters, E. E. (2005). The World Health Organization Adult ADHD Self-Report Scale (ASRS): A 
short screening scale for use in the general population. Psychological medicine, 35(2), 245256. doi:10.1017/S0033291704002892

Killingsworth, M. A., \& Gilbert, D. T. (2010). A wandering mind is an unhappy mind. Science, 330(6006), 932. doi:10.1126/science.1192439

Kretzschmar, A., \& Gignac, G. E. (2019). At what sample size do latent variable correlations stabilize? Journal of Research in Personality, 80, 17-22. doi:10.1016/j.jrp.2019.03.007

Lovibond, S. H., \& Lovibond, P. F. (1995). Manual for the Depression Anxiety Stress Scales (2nd ed.). Sydney, Australia: Psychology Foundation of Australia.

Marcusson-Clavertz, D., \& Kjell, O. N. E. (2019). Psychometric properties of the spontaneous and deliberate mind-wandering scales. European Journal of Psychological Assessment, 35(6), 878-890. doi:10.1027/1015-5759/a000470

Mason, M. F., Norton, M. I., Van Horn, J. D., Wegner, D. M., Grafton, S. T., \& Macrae, C. N. (2007). Wandering minds: The default network and stimulus-independent thought. Science, 315(5810), 393-395. doi:10.1126/science.1131295

Mills, C., \& Christoff, K. (2018). Finding consistency in boredom by appreciating its instability. Trends in Cognitive Sciences, 22(9), 744-747. doi:10.1016/j.tics.2018.07.001

Milyavskaya, M., Inzlicht, M., Johnson, T., \& Larson, M. J. (2019). Reward sensitivity following boredom and cognitive effort: A high-powered neurophysiological investigation. Neuropsychologia, 123, 159-168. doi:10.1016/j.neuropsychologia.2018.03.033

Mooneyham, B. W., \& Schooler, J. W. (2013). The costs and benefits of mind-wandering: A review. Canadian Journal of Experimental Psychology, 67(1), 11-18. doi:10.1037/a0031569

Mrazek, M. D., Phillips, D. T., Franklin, M. S., Broadway, J. M., \& Schooler, J. W. (2013). Young and restless: validation of the Mind-Wandering Questionnaire (MWQ) reveals disruptive impact of mind-wandering for youth. Frontiers in Psychology, 4:560. doi:10.3389/fpsyg.2013.00560 
Mugon, J., Struk, A., \& Danckert, J. (2018). A failure to launch: Regulatory modes and boredom proneness. Frontiers in Psychology, 9:1126. doi:10.3389/fpsyg.2018.01126

Oppenheimer, D. M., Meyvis, T., \& Davidenko, N. (2009). Instructional manipulation checks: Detecting satisficing to increase statistical power. Journal of Experimental Social Psychology, 45(4), 867-872. doi:10.1016/j.jesp.2009.03.009

Opsahl, T., Agneessens, F., \& Skvoretz, J. (2010). Node centrality in weighted networks: Generalizing degree and shortest paths. Social Networks, 32(3), 245-251. doi: $10.1016 /$ j.socnet.2010.03.006

Pattyn, N., Neyt, X., Henderickx, D., \& Soetens, E. (2008). Psycho-physiological investigation of vigilance decrement: Boredom or cognitive fatigue? Physiology \& Behavior, 93(1-2), 369-378. doi:10.1016/j.physbeh.2007.09.016

R Core Team. (2018). $R$ : A Language and environment for statistical computing. [Computer software]. Retrieved from https://cran.r-project.org/.

Raffaelli, Q., Mills, C., \& Christoff, K. (2018). The knowns and unknowns of boredom: A review of the literature. Experimental Brain Research, 236(9), 2451-2462. doi:10.1007/s00221-017-4922-7

Rammstedt, B., Danner, D., Soto, C. J., \& John, O. P. (2018). Validation of the short and extrashort forms of the Big Five Inventory-2 (BFI-2) and their German adaptations. European Journal of Psychological Assessment, Advance online publication. doi:10.1027/1015$5759 / \mathrm{a} 000481$

Raykov, T. (1997). Estimation of composite reliability for congeneric measures. Applied Psychological Measurement, 21(2), 173-184. doi:10.1177/01466216970212006

Raykov, T. (2004). Behavioral scale reliability and measurement invariance evaluation using latent variable modeling. Behavior Therapy, 35(2), 299-331. doi:10.1016/S00057894(04)80041-8 
Revelle, W. (2019). psych: Procedures for Psychological, Psychometric, and Personality Research. [R package]. Retrieved from https://cran.r-project.org/package=psych.

Rosseel, Y., et al. (2018). lavaan: Latent variable analysis. [R package]. Retrieved from https://cran.r-project.org/package=lavaan.

Schredl, M., Berres, S., Klingauf, A., Schellhaas, S., \& Göritz, A., S. (2014). The Mannheim Dream Questionnaire (MADRE): Retest reliability, age and gender effects. International Journal of Dream Research, 7(2), 141-147. doi:10.11588/ijodr.2014.2.16675

Schredl, M., Rieger, J., \& Göritz, A. S. (2018). Measuring lucid dreaming skills: A new questionnaire (LUSK). International Journal of Dream Research, 11(1), 54-61. doi:10.11588/ijodr.2018.1.44040

Seli, P., Carriere, J. S. A., \& Smilek, D. (2015). Not all mind-wandering is created equal: Dissociating deliberate from spontaneous mind-wandering. Psychological Research, 79(5), 750-758. doi:10.1007/s00426-014-0617-x

Seli, P., Kane, M. J., Metzinger, T., Smallwood, J., Schacter, D. L., Maillet, D., . . \& Smilek, D. (2018). The family-resemblances framework for mind-wandering remains well clad. Trends in Cognitive Sciences, 22(11), 959-961. doi:10.1016/j.tics.2018.07.007

Seli, P., Risko, E. F., \& Smilek, D. (2016). Assessing the associations among trait and state levels of deliberate and spontaneous mind-wandering. Consciousness and Cognition, 41, 50-56. doi:10.1016/j.concog.2016.02.002

Seli, P., Risko, E. F., Smilek, D., \& Schacter, D. L. (2016). Mind-wandering with and without intention. Trends in Cognitive Sciences, 20(8), 605-617. doi:10.1016/j.tics.2016.05.010.

Smallwood, J., \& Schooler, J. W. (2006). The restless mind. Psychological Bulletin, 132(6), 946-958. doi:10.1037/0033-2909.132.6.946 
Smallwood, J., \& Schooler, J. W. (2015). The science of mind-wandering: Empirically navigating the stream of consciousness. Annual Review of Psychology, 66(1), 487-518. doi:10.1146/ annurev-psych-010814-015331.

Sommers, J., \& Vodanovich, S. J. (2000). Boredom proneness: Its relationship to psychological- and physical-health symptoms. Journal of Clinical Psychology, 56(1), 149155. doi:10.1002/(SICI)1097-4679(200001)56:1<149::AID-JCLP14>3.0.CO;2-Y

Soto, C. J., \& John, O. P. (2017). Short and extra-short forms of the Big Five Inventory-2: The BFI-2-S and BFI-2-XS. Journal of Research in Personality, 68, 69-81. doi:10.1016/j.jrp.2017.02.004

Spitzer, R. L., Kroenke, K., Williams, J. W., \& Löwe, B. (2006). A brief measure for assessing generalized anxiety disorder: The GAD-7. Archives of Internal Medicine, 166(10), 1092-1097. doi:10.1001/archinte.166.10.1092

Spreng, R. N., Mar, R. A., \& Kim, A. S. (2009). The common neural basis of autobiographical memory, prospection, navigation, theory of mind, and the default mode: A quantitative meta-analysis. Journal of Cognitive Neuroscience, 21(3), 489-510. doi:10.1162/jocn.2008.21029

Stawarczyk, D., Majerus, S., Maj, M., Van der Linden, M., \& D’Argembeau, A. (2011). Mind-wandering: Phenomenology and function as assessed with a novel experience sampling method. Acta Psychologica, 136(3), 370-381. doi:10.1016/j.actpsy.2011.01.002

Struk, A. A., Carriere, J. S. A., Cheyne, J. A., \& Danckert, J. (2017). A short boredom proneness scale: Development and psychometric properties. Assessment, 24(3), 346-359. doi:10.1177/1073191115609996

The jamovi project. (2019). jamovi (Version 0.9) [Computer Software]. Retrieved from https://www.jamovi.org.

Vannucci, M., \& Chiorri, C. (2018). Individual differences in self-consciousness and mindwandering: Further evidence for a dissociation between spontaneous and deliberate mind- 
wandering. Personality and Individual Differences, 121, 57-61.

doi:10.1016/j.paid.2017.09.022

Vodanovich, S. J., Wallace, J. C., \& Kass, S. J. (2005). A confirmatory approach to the factor structure of the Boredom Proneness Scale: Evidence for a two-factor short form. Journal of Personality Assessment, 85(3), 295-303. doi:10.1207/ s15327752jpa8503_05

Weibel, D., Martarelli, C. S., Häberli, D., \& Mast, F. W. (2018). The fantasy questionnaire: A measure to assess imaginative and creative fantasy. Journal of Personality Assessment, 100(4), 431-443. doi:10.1080/00223891.2017.1331913

Westgate, E. C., \& Wilson, T. D. (2018). Boring thoughts and bored minds: The MAC model of boredom and cognitive engagement. Psychological Review, 125(5), 689-713. doi:10.1037/rev0000097

Wilson, T. D., Reinhard, D. A., Westgate, E. C., Gilbert, D. T., Ellerbeck, N., Hahn, C., ... \& Shaked, A. (2014). Just think: The challenges of the disengaged mind. Science, 345(6192), 75-77. doi:10.1126/science. 1250830

Wolff, W., \& Martarelli, C. S. (2020). Bored into depletion? Towards a tentative integration of perceived self-control exertion and boredom as guiding signals for goal-directed behavior. Perspectives on Psychological Science. doi:10.1177/1745691620921394

Zedelius, C. M., \& Schooler, J. W. (2016) The richness of inner experience: Relating styles of daydreaming to creative processes. Frontiers in Psychology. 6:2063. doi:10.3389/fpsyg.2015.02063

Zhiyan, T., \& Singer, J. L. (1996). Daydreaming styles, emotionality and the big five personality dimensions. Imagination Cognition and Personality, 16(4), 399-414. doi:10.2190/ATEH-96EV-EXYX-2ADB 


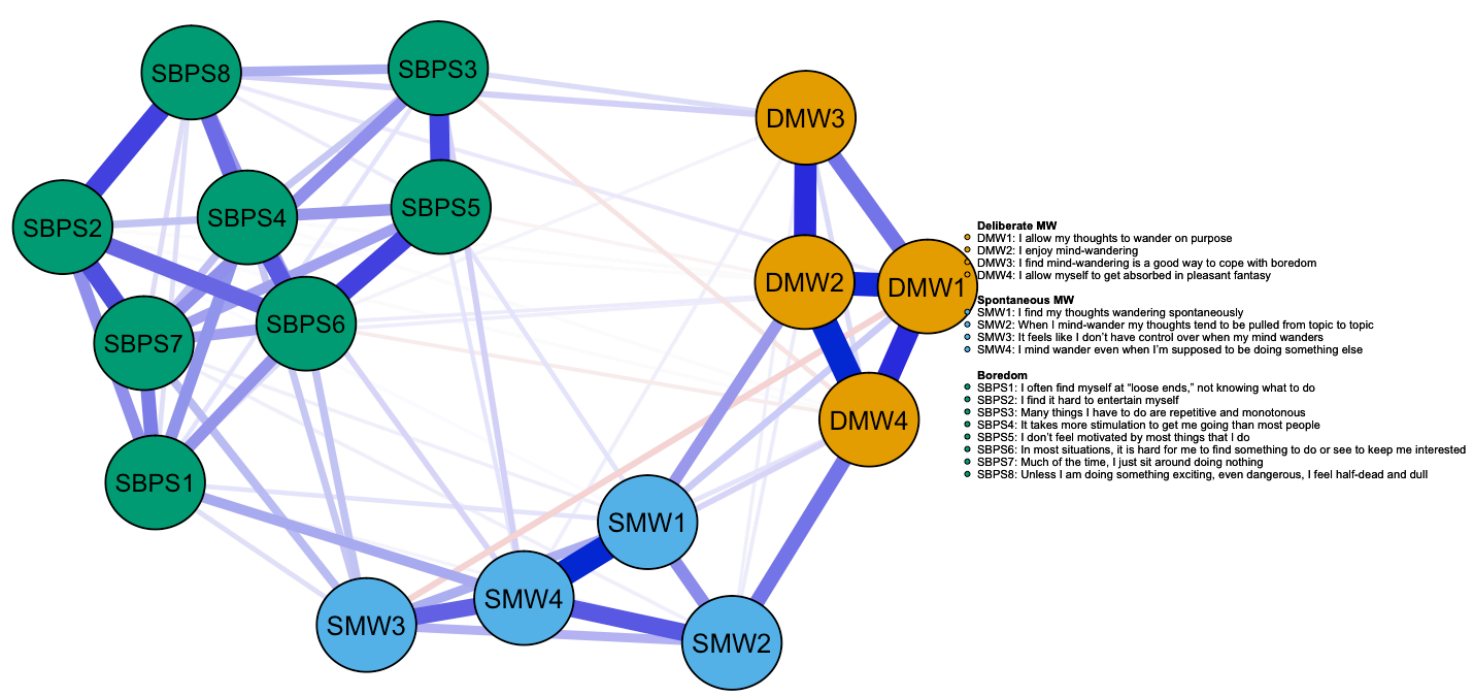

Figure 1. Network analysis displaying the relationships between the 16 items of the SDMWS and the SBPS based on EBICglasso. 

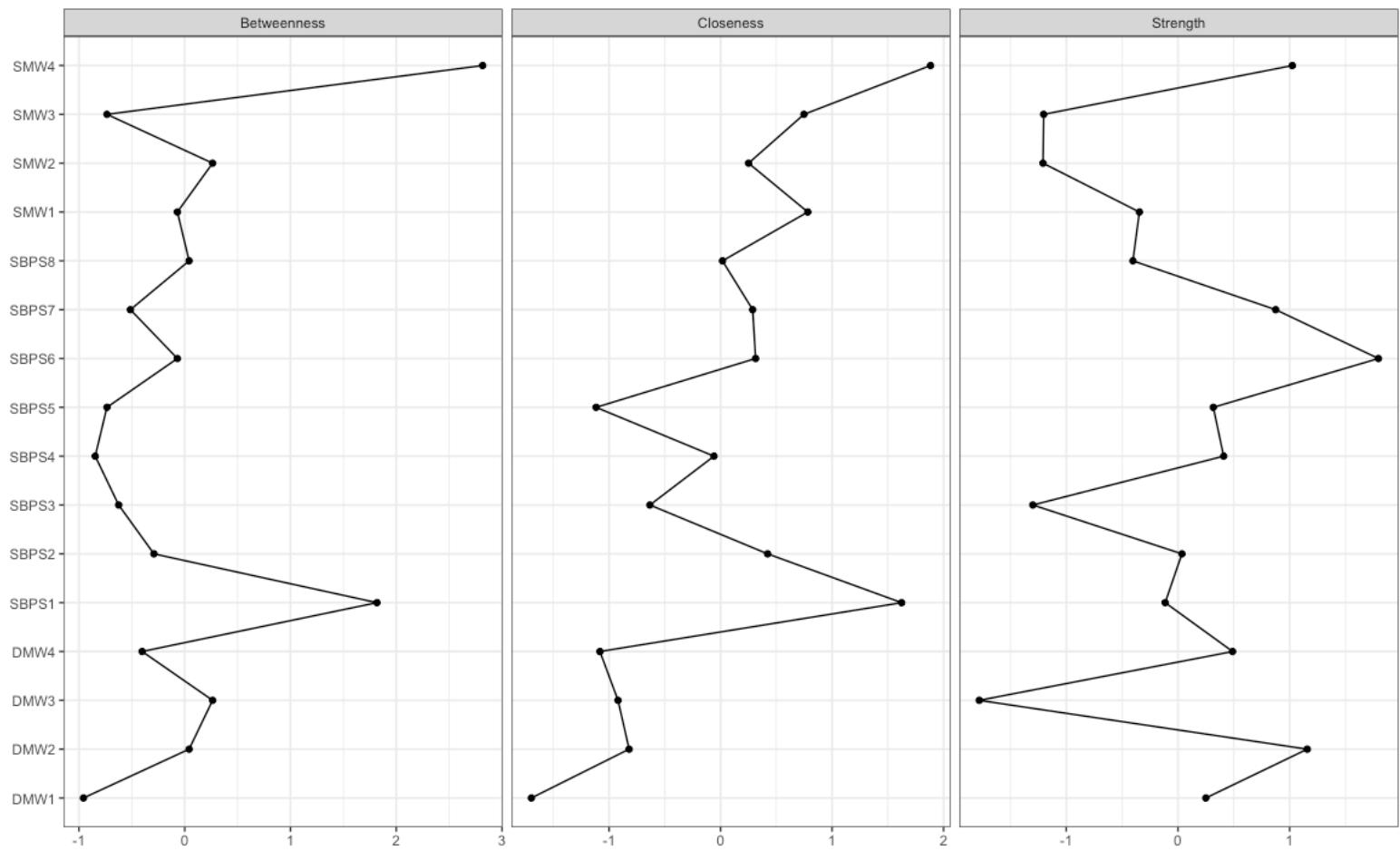

Figure 2. z-scored centrality metrics (betweenness, closeness, strength) for items of the SDMWS and SBPS. 


\section{Table 1}

\section{Scales with answers}

\begin{tabular}{ll}
\hline SDMWS German version & Bitte wählen Sie bei den folgenden Aussagen diejenigen, die \\
& am genauesten Ihr tägliches Tagträumen beschreiben. \\
\hline DMW1 - Ich lasse meine Gedanken absichtlich abschweifen. & 1 (Selten) - 7 (Oft) \\
DMW2 - Ich geniesse es, mit den Gedanken abzuschweifen. & 1 (Selten) - 7 (Oft) \\
DMW3 - Ich finde, mit den Gedanken abzuschweifen, ist eine gute & 1 (Stimme überhaupt nicht zu) - 7 (Stimme voll und ganz zu) \\
Möglichkeit, mit Langeweile umzugehen. & \\
DMW4 - Ich erlaube es mir, in angenehmen Fantasien einzutauchen. & 1 (Selten) - 7 (Oft) \\
SMW1 - Ich bemerke, wie meine Gedanken spontan abschweifen. & 1 (Selten) - 7 (Oft) \\
SMW2 - Wenn ich mit meinen Gedanken abschweife, werden sie meist & 1 (Selten) - 7 (Oft) \\
von Thema zu Thema gezogen. & \\
SMW3 - Es fühlt sich an, als ob ich keine Kontrolle darüber hätte, & 1 (Stimme überhaupt nicht zu) - 7 (Stimme voll und ganz zu) \\
wann meine Gedanken abschweifen. & \\
SMW4 - Meine Gedanken schweifen ab, auch wenn ich etwas anderes & 1 (Selten) - 7 (Oft) \\
tun sollte. &
\end{tabular}

\begin{tabular}{ll}
\hline SDMWS Original & $\begin{array}{l}\text { For the following statements please select the answer that } \\
\text { most accurately reflects your everyday mind-wandering }\end{array}$ \\
\hline DMW1 - I allow my thoughts to wander on purpose. & 1 (Rarely) - 7 (A lot) \\
DMW2 - I enjoy mind-wandering. & 1 (Rarely) - 7 (A lot) \\
DMW3 - I find mind-wandering is a good way to cope with boredom. & 1 (Not at all true) - 7 (very true) \\
DMW4 - I allow myself to get absorbed in pleasant fantasy. & 1 (Rarely) - 7 (A lot) \\
SMW1 - I find my thoughts wandering spontaneously. & 1 (Rarely) - 7 (A lot) \\
SMW2 - When I mind-wander my thoughts tend to be pulled from & 1 (Rarely) - 7 (A lot) \\
topic to topic. & \\
SMW3 - It feels like I don't have control over when my mind wanders. & 1 (Not at all true) - 7 (very true) \\
SMW4 - I mind wander even when I'm supposed to be doing & 1 (Rarely) - 7 (A lot) \\
something else. & \\
\hline
\end{tabular}

\begin{tabular}{ll}
\hline SBPS German version & Bitte geben Sie an, wie sehr folgende \\
& Aussagen auf Sie zutreffen. \\
\hline SBPS1 - Ich stehe häufig vor Unerledigtem und weiss nicht, was ich tun soll. & 1 (Stimme überhaupt nicht zu) - 7 \\
& (Stimme voll und ganz zu) \\
\hline
\end{tabular}


SBPS3 - Viele Dinge, die ich tun muss, sind repetitiv und monoton.

SBPS4 - Es braucht mehr Anregung, um mich in die Gänge zu bringen, als bei den meisten anderen Menschen.

SBPS5 - Die meisten Dinge, die ich mache, motivieren mich nicht

SBPS6 - In den meisten Situationen fällt es mir schwer, etwas zu finden, was ich tun oder sehen kann, um mein Interesse aufrechtzuerhalten.

SBPS7 - Einen Grossteil der Zeit sitze ich einfach rum und mache nichts.

SBPS8 - Ich fühle mich halb tot und stumpf, es sei denn, ich mache etwas Aufregendes oder sogar Gefährliches.
1 (Stimme überhaupt nicht zu) - 7

(Stimme voll und ganz zu)

1 (Stimme überhaupt nicht zu) - 7

(Stimme voll und ganz zu)

1 (Stimme überhaupt nicht zu) - 7

(Stimme voll und ganz zu)

1 (Stimme überhaupt nicht zu) - 7

(Stimme voll und ganz zu)

1 (Stimme überhaupt nicht zu) - 7

(Stimme voll und ganz zu)

1 (Stimme überhaupt nicht zu) -7

(Stimme voll und ganz zu)

\section{SBPS Original}

SBPS1 - I often find myself at "loose ends," not knowing what to do.

1 (Strongly disagree) - 7 (strongly agree)

SBPS2 - I find it hard to entertain myself.

1 (Strongly disagree) -7 (strongly agree)

SBPS3 - Many things I have to do are repetitive and monotonous.

1 (Strongly disagree) - 7 (strongly agree)

SBPS4 - It takes more stimulation to get me going than most people.

1 (Strongly disagree) - 7 (strongly agree)

SBPS5 - I don't feel motivated by most things that I do.

1 (Strongly disagree) -7 (strongly agree)

SBPS6 - In most situations, it is hard for me to find something to do or see to keep me

1 (Strongly disagree) -7 (strongly agree) interested.

SBPS7 - Much of the time, I just sit around doing nothing.

1 (Strongly disagree) - 7 (strongly agree)

SBPS8 - Unless I am doing something exciting, even dangerous, I feel half-dead and

1 (Strongly disagree) - 7 (strongly agree) dull. 
Table 2

Descriptive summary of measures

\begin{tabular}{|c|c|c|c|c|c|c|c|}
\hline Sample & Measure & Mean (SD) & Skewness & Kurtosis & Alpha & Omega & $\begin{array}{l}\text { Composite } \\
\text { reliability }\end{array}$ \\
\hline German-speaking & DMW & $4.24(1.42)$ & -0.21 & -0.71 & 0.808 & 0.816 & 0.816 \\
\hline$(\mathrm{N}=416)$ & SMW & $3.90(1.25)$ & -0.08 & -0.34 & 0.731 & 0.739 & 0.741 \\
\hline$(\mathrm{N}=410)$ & SBPS & $2.28(1.03)$ & 1.23 & 1.49 & 0.865 & 0.867 & 0.867 \\
\hline$(\mathrm{N}=402)$ & BFI-Open & $3.77(0.64)$ & -0.17 & -0.25 & 0.655 & 0.660 & 0.653 \\
\hline US & DMW & $4.46(1.48)$ & -0.44 & $-0-53$ & 0.873 & 0.876 & 0.876 \\
\hline \multirow[t]{2}{*}{$(\mathrm{N}=364)$} & SMW & $4.07(1.43)$ & -0.25 & -0.56 & 0.815 & 0.824 & 0.821 \\
\hline & SBPS & $3.06(1.53)$ & -0.38 & -0.94 & 0.921 & 0.923 & 0.923 \\
\hline
\end{tabular}


Table 3

Factor loadings in the German-speaking sample

\begin{tabular}{|c|c|c|c|c|c|c|c|c|}
\hline \multirow[b]{2}{*}{ Factor } & \multirow[b]{2}{*}{ Indicator } & \multirow[b]{2}{*}{ Estimate } & \multirow[b]{2}{*}{ SE } & \multicolumn{2}{|c|}{ 95\% Confidence Interval } & \multirow[b]{2}{*}{$\mathbf{Z}$} & \multirow[b]{2}{*}{$\mathbf{p}$} & \multirow[b]{2}{*}{ Stand. Estimate } \\
\hline & & & & Lower & Upper & & & \\
\hline \multirow[t]{4}{*}{ DMW } & DMW1 & 1.33 & 0.08 & 1.17 & 1.50 & 16.11 & $<.001$ & 0.74 \\
\hline & DMW2 & 1.38 & 0.08 & 1.23 & 1.53 & 18.13 & $<.001$ & 0.81 \\
\hline & DMW3 & 1.06 & 0.09 & 0.88 & 1.25 & 11.38 & $<.001$ & 0.56 \\
\hline & DMW4 & 1.33 & 0.08 & 1.18 & 1.48 & 17.11 & $<.001$ & 0.77 \\
\hline \multirow[t]{4}{*}{ SMW } & SMW1 & 0.92 & 0.08 & 0.76 & 1.08 & 11.24 & $<.001$ & 0.58 \\
\hline & SMW2 & 0.94 & 0.09 & 0.77 & 1.12 & 10.41 & $<.001$ & 0.54 \\
\hline & SMW3 & 1.00 & 0.08 & 0.84 & 1.16 & 12.39 & $<.001$ & 0.62 \\
\hline & SMW4 & 1.47 & 0.09 & 1.30 & 1.65 & 16.53 & $<.001$ & 0.83 \\
\hline
\end{tabular}

Factor loadings in the US sample

\begin{tabular}{|c|c|c|c|c|c|c|c|c|}
\hline \multirow[b]{2}{*}{ Factor } & \multirow[b]{2}{*}{ Indicator } & \multirow[b]{2}{*}{ Estimate } & \multirow[b]{2}{*}{ SE } & \multicolumn{2}{|c|}{ 95\% Confidence Interval } & \multirow[b]{2}{*}{$\mathbf{Z}$} & \multirow[b]{2}{*}{$\mathbf{p}$} & \multirow[b]{2}{*}{ Stand. Estimate } \\
\hline & & & & Lower & Upper & & & \\
\hline \multirow[t]{4}{*}{ DMW } & DMW1 & 1.36 & 0.09 & 1.19 & 1.53 & 15.92 & $<.001$ & 0.76 \\
\hline & DMW2 & 1.39 & 0.08 & 1.23 & 1.54 & 17.60 & $<.001$ & 0.82 \\
\hline & DMW3 & 1.32 & 0.09 & 1.15 & 1.49 & 15.08 & $<.001$ & 0.75 \\
\hline & DMW4 & 1.47 & 0.08 & 1.32 & 1.63 & 18.43 & $<.001$ & 0.86 \\
\hline \multirow[t]{4}{*}{ SMW } & SMW1 & 1.60 & 0.08 & 1.43 & 1.76 & 19.07 & $<.001$ & 0.92 \\
\hline & SMW2 & 1.40 & 0.09 & 1.22 & 1.58 & 15.10 & $<.001$ & 0.79 \\
\hline & SMW3 & 0.86 & 0.09 & 0.67 & 1.04 & 9.09 & $<.001$ & 0.47 \\
\hline & SMW4 & 1.34 & 0.09 & 1.17 & 1.51 & 15.12 & $<.001$ & 0.75 \\
\hline
\end{tabular}




\section{Table 4}

Measurement invariance analyses on the SDMWS and the SBPS across samples

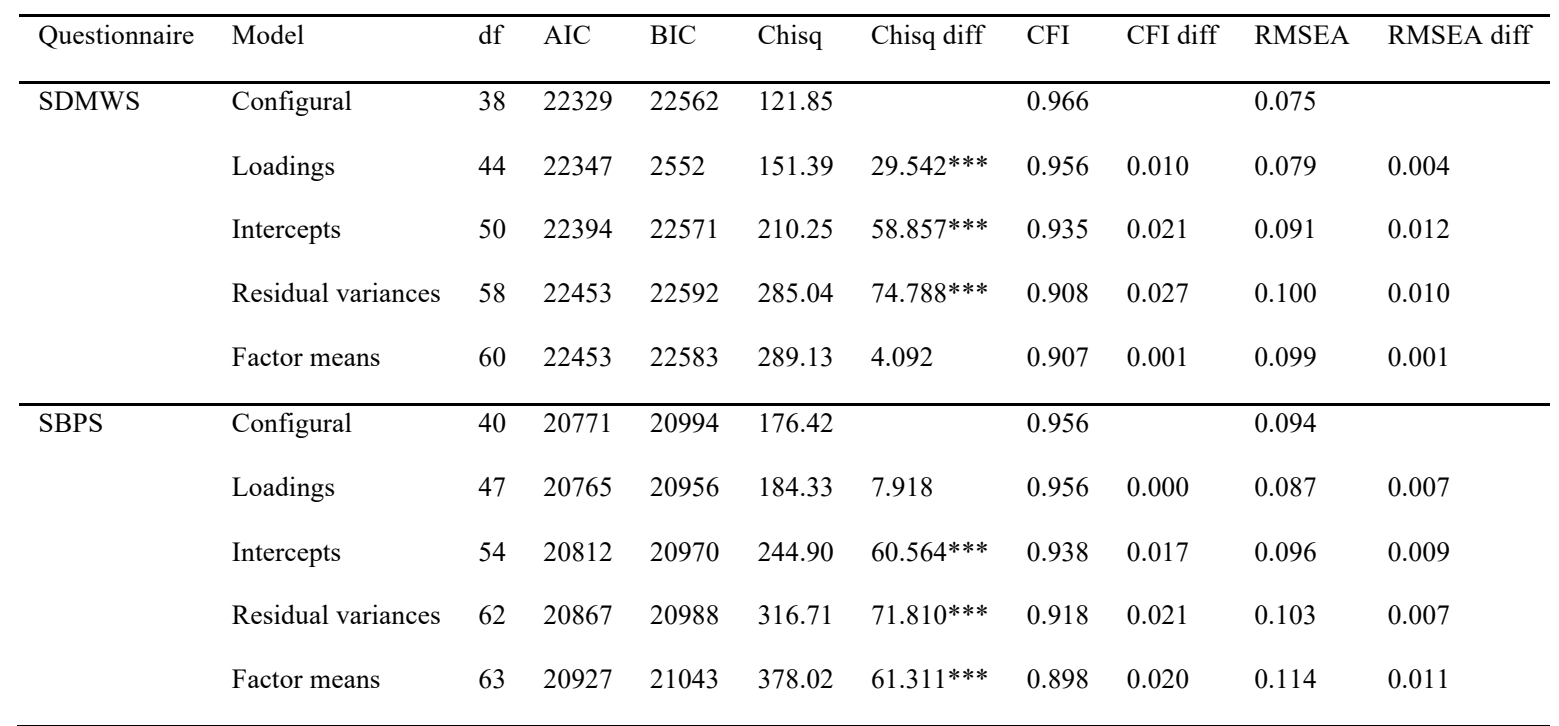

Note. ${ }^{* * *}$. Difference is significant at the 0.001 level (two-tailed). 
Table 5

Factor loadings in the German-speaking sample

\begin{tabular}{|c|c|c|c|c|c|c|c|c|}
\hline \multirow[b]{2}{*}{ Factor } & \multirow[b]{2}{*}{ Indicator } & \multirow[b]{2}{*}{ Estimate } & \multirow[b]{2}{*}{ SE } & \multicolumn{2}{|c|}{ 95\% Confidence Interval } & \multirow[b]{2}{*}{$\mathbf{Z}$} & \multirow[b]{2}{*}{$\mathbf{p}$} & \multirow[b]{2}{*}{ Stand. Estimate } \\
\hline & & & & Lower & Upper & & & \\
\hline \multirow[t]{8}{*}{ SBPS } & SBPS1 & 1.00 & 0.08 & 0.85 & 1.15 & 13.34 & $<.001$ & 0.63 \\
\hline & SBPS2 & 0.93 & 0.06 & 0.81 & 1.05 & 14.96 & $<.001$ & 0.69 \\
\hline & SBPS3 & 0.80 & 0.07 & 0.66 & 0.94 & 11.03 & $<.001$ & 0.54 \\
\hline & SBPS4 & 1.06 & 0.07 & 0.93 & 1.20 & 15.14 & $<.001$ & 0.69 \\
\hline & SBPS5 & 1.06 & 0.06 & 0.94 & 1.19 & 16.96 & $<.001$ & 0.75 \\
\hline & SBPS6 & 1.11 & 0.06 & 0.98 & 1.23 & 17.47 & $<.001$ & 0.77 \\
\hline & SBPS7 & 0.92 & 0.06 & 0.80 & 1.04 & 14.72 & $<.001$ & 0.68 \\
\hline & SBPS8 & 0.77 & 0.06 & 0.66 & 0.89 & 12.85 & $<.001$ & 0.61 \\
\hline
\end{tabular}

Factor loadings in the US sample

\begin{tabular}{|c|c|c|c|c|c|c|c|c|}
\hline \multirow[b]{2}{*}{ Factor } & \multirow[b]{2}{*}{ Indicator } & \multirow[b]{2}{*}{ Estimate } & \multirow[b]{2}{*}{ SE } & \multicolumn{2}{|c|}{ 95\% Confidence Interval } & \multirow[b]{2}{*}{$\mathbf{Z}$} & \multirow[b]{2}{*}{$\mathbf{p}$} & \multirow[b]{2}{*}{ Stand. Estimate } \\
\hline & & & & Lower & Upper & & & \\
\hline \multirow[t]{8}{*}{ SBPS } & SBPS1 & 1.57 & 0.08 & 1.40 & 1.73 & 18.96 & $<.001$ & 0.83 \\
\hline & SBPS2 & 1.44 & 0.08 & 1.28 & 1.59 & 18.01 & $<.001$ & 0.80 \\
\hline & SBPS3 & 1.14 & 0.09 & 0.95 & 1.32 & 12.09 & $<.001$ & 0.59 \\
\hline & SBPS4 & 1.59 & 0.09 & 1.41 & 1.76 & 17.90 & $<.001$ & 0.80 \\
\hline & SBPS5 & 1.43 & 0.09 & 1.26 & 1.61 & 16.25 & $<.001$ & 0.74 \\
\hline & SBPS6 & 1.68 & 0.08 & 1.52 & 1.84 & 20.05 & $<.001$ & 0.86 \\
\hline & SBPS7 & 1.51 & 0.08 & 1.35 & 1.68 & 18.20 & $<.001$ & 0.80 \\
\hline & SBPS8 & 1.37 & 0.08 & 1.21 & 1.53 & 16.46 & $<.001$ & 0.75 \\
\hline
\end{tabular}


Table 6

Correlations among constructs divided by sample

\begin{tabular}{lllll}
\hline & DMW & SMW & SBPS & BFI-Open \\
\hline DMW & - & $0.273 * * *$ & $0.162 * *$ & $0.214 * * *$ \\
& & & $0.480 * * *$ & -0.036 \\
SMW & $0.575^{* * *}$ & - & & $-0.203 * *$ \\
SBPS & $0.252^{* * *}$ & $0.548 * * *$ & - & \\
\hline
\end{tabular}

Note. Correlations for the German-speaking sample are presented above the diagonal and correlations for the US sample are presented below the diagonal. ***. Correlation is significant at the 0.001 level (two-tailed) $* *$.

Correlation is significant at the 0.01 level (two-tailed). 


\section{Appendix A}

One-factorial model for the SDMWS

Factor loadings in the German-speaking sample

\begin{tabular}{|c|c|c|c|c|c|c|c|c|}
\hline \multirow[b]{2}{*}{ Factor } & \multirow[b]{2}{*}{ Indicator } & \multirow[b]{2}{*}{ Estimate } & \multirow[b]{2}{*}{ SE } & \multicolumn{2}{|c|}{ 95\% Confidence Interval } & \multirow[b]{2}{*}{$\mathbf{Z}$} & \multirow[b]{2}{*}{$\mathbf{p}$} & \multirow[b]{2}{*}{ Stand. Estimate } \\
\hline & & & & Lower & Upper & & & \\
\hline \multirow[t]{8}{*}{ SDMW } & DMW1 & 1.30 & 0.08 & 1.13 & 1.46 & 15.60 & $<.001$ & 0.72 \\
\hline & DMW2 & 1.37 & 0.08 & 1.23 & 1.52 & 18.19 & $<.001$ & 0.81 \\
\hline & DMW3 & 1.05 & 0.09 & 0.87 & 1.24 & 11.30 & $<.001$ & 0.56 \\
\hline & DMW4 & 1.33 & 0.08 & 1.17 & 1.48 & 17.13 & $<.001$ & 0.77 \\
\hline & SMW1 & 0.60 & 0.08 & 0.43 & 0.76 & 7.24 & $<.001$ & 0.38 \\
\hline & SMW2 & 0.61 & 0.09 & 0.43 & 0.79 & 6.66 & $<.001$ & 0.35 \\
\hline & SMW3 & 0.26 & 0.09 & 0.08 & 0.43 & 2.92 & 0.003 & 0.16 \\
\hline & SMW4 & 0.52 & 0.10 & 0.33 & 0.71 & 5.45 & $<.001$ & 0.29 \\
\hline
\end{tabular}

Test for exact fit /

German-speaking sample

\begin{tabular}{ccc}
$\boldsymbol{\chi}^{2}$ & $\mathbf{d f}$ & $\mathbf{p}$ \\
\hline 335.51 & 20 & $<.001$ \\
\hline
\end{tabular}

Fit measures / German-speaking sample

RMSEA 90\% CI

\begin{tabular}{cccccc}
\cline { 4 - 5 } CFI & TLI & SRMR & RMSEA & Lower & Upper \\
\hline 0.68 & 0.55 & 0.14 & 0.19 & 0.18 & 0.21 \\
\hline
\end{tabular}


Factor loadings in the US sample

\begin{tabular}{|c|c|c|c|c|c|c|c|c|}
\hline \multirow[b]{2}{*}{ Factor } & \multirow[b]{2}{*}{ Indicator } & \multirow[b]{2}{*}{ Estimate } & \multirow[b]{2}{*}{$\mathbf{S E}$} & \multicolumn{2}{|c|}{ 95\% Confidence Interval } & \multirow[b]{2}{*}{$\mathbf{Z}$} & \multirow[b]{2}{*}{$\mathbf{p}$} & \multirow[b]{2}{*}{ Stand. Estimate } \\
\hline & & & & Lower & Upper & & & \\
\hline \multirow[t]{8}{*}{ SDMW } & DMW1 & 1.37 & 0.08 & 1.20 & 1.53 & 16.56 & $<.001$ & 0.77 \\
\hline & DMW2 & 1.35 & 0.08 & 1.20 & 1.50 & 17.50 & $<.001$ & 0.80 \\
\hline & DMW3 & 1.19 & 0.09 & 1.02 & 1.35 & 13.88 & $<.001$ & 0.67 \\
\hline & DMW4 & 1.39 & 0.08 & 1.24 & 1.54 & 18.15 & $<.001$ & 0.81 \\
\hline & SMW1 & 1.30 & 0.08 & 1.14 & 1.47 & 15.76 & $<.001$ & 0.75 \\
\hline & SMW2 & 1.19 & 0.09 & 1.03 & 1.36 & 13.91 & $<.001$ & 0.68 \\
\hline & SMW3 & 0.63 & 0.10 & 0.43 & 0.83 & 6.27 & $<.001$ & 0.34 \\
\hline & SMW4 & 1.21 & 0.09 & 1.04 & 1.38 & 13.80 & $<.001$ & 0.68 \\
\hline
\end{tabular}

Test for exact fit

US sample

\begin{tabular}{ccc}
\hline $\boldsymbol{\chi}^{\mathbf{2}}$ & $\mathbf{d f}$ & $\mathbf{p}$ \\
\hline 257.52 & 20 & $<.001$ \\
\hline
\end{tabular}

Fit measures / US sample

\begin{tabular}{ccccccc}
\hline & & & & \multicolumn{2}{c}{ RMSEA 90\% CI } \\
\cline { 5 - 6 } CFI & TLI & SRMR & RMSEA & Lower & Upper \\
\hline \multirow{2}{*}{0.84} & 0.78 & 0.08 & 0.18 & 0.16 & 0.20 \\
\hline
\end{tabular}


Appendix B

Network of correlations

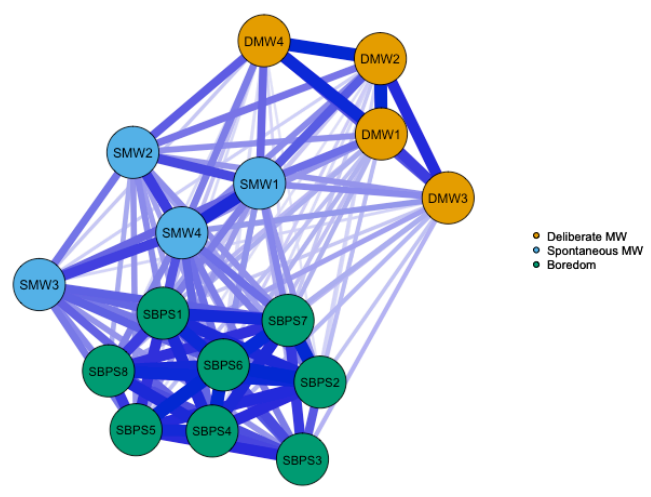

Network of partial correlations

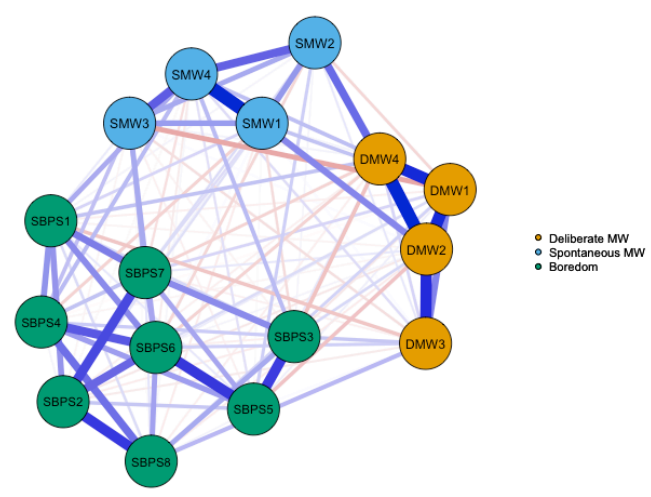




\section{Appendix C}

Weights of the estimated network using EBICglasso (see Figure 1).

\begin{tabular}{|c|c|c|c|}
\hline From & & To & Weight \\
\hline 1 & --- & 2 & 0.31 \\
\hline 1 & -- & 3 & 0.17 \\
\hline 2 & -- & 3 & 0.3 \\
\hline 1 & -- & 4 & 0.3 \\
\hline 2 & -- & 4 & 0.33 \\
\hline 3 & -- & 4 & 0.05 \\
\hline 1 & --- & 5 & 0.07 \\
\hline 2 & --- & 5 & 0.15 \\
\hline 4 & --- & 5 & 0.04 \\
\hline 2 & -- & 6 & 0.03 \\
\hline 3 & --- & 6 & 0.01 \\
\hline 4 & --- & 6 & 0.19 \\
\hline 5 & -- & 6 & 0.14 \\
\hline 1 & -- & 7 & -0.13 \\
\hline 5 & --- & 7 & 0.13 \\
\hline 6 & --- & 7 & 0.12 \\
\hline 3 & -- & 8 & 0.01 \\
\hline 4 & -- & 8 & 0.08 \\
\hline 5 & --- & 8 & 0.33 \\
\hline 6 & --- & 8 & 0.21 \\
\hline 7 & --- & 8 & 0.21 \\
\hline 5 & -- & 9 & 0.04 \\
\hline 6 & --- & 9 & 0.02 \\
\hline 7 & --- & 9 & 0.04 \\
\hline 8 & --- & 9 & 0.11 \\
\hline 2 & -- & 10 & -0.03 \\
\hline 4 & --- & 10 & -0.01 \\
\hline 5 & --- & 10 & 0.02 \\
\hline 9 & --- & 10 & 0.15 \\
\hline 3 & --- & 11 & 0.07 \\
\hline 4 & --- & 11 & -0.07 \\
\hline 8 & --- & 11 & 0.07 \\
\hline 9 & -- & 11 & 0.03 \\
\hline 2 & --- & 12 & -0.02 \\
\hline 4 & --- & 12 & -0.01 \\
\hline 7 & --- & 12 & 0.07 \\
\hline 8 & -- & 12 & 0.06 \\
\hline 9 & -- & 12 & 0.15 \\
\hline 10 & -- & 12 & 0.01 \\
\hline 11 & -- & 12 & 0.07 \\
\hline 2 & -- & 13 & -0.04 \\
\hline 6 & --- & 13 & 0.05 \\
\hline 8 & --- & 13 & 0.03 \\
\hline 9 & --- & 13 & 0.04 \\
\hline 10 & --- & 13 & 0.07 \\
\hline 11 & --- & 13 & 0.25 \\
\hline 12 & --- & 13 & 0.13 \\
\hline 1 & --- & 14 & 0.06 \\
\hline 3 & -- & 14 & 0.03 \\
\hline 4 & -- & 14 & -0.06 \\
\hline 7 & --- & 14 & 0.08 \\
\hline 9 & --- & 14 & 0.14 \\
\hline 10 & -- & 14 & 0.2 \\
\hline 12 & --- & 14 & 0.22 \\
\hline 13 & --- & 14 & 0.26 \\
\hline 1 & --- & 15 & 0.04 \\
\hline 5 & -- & 15 & 0.01 \\
\hline 6 & --- & 15 & 0.02 \\
\hline 7 & --- & 15 & 0.09 \\
\hline 9 & --- & 15 & 0.17 \\
\hline 10 & -- & 15 & 0.24 \\
\hline 11 & --- & 15 & 0.14 \\
\hline 12 & --- & 15 & 0.08 \\
\hline 13 & --- & 15 & 0.12 \\
\hline 14 & --- & 15 & 0.12 \\
\hline 1 & --- & 16 & 0.04 \\
\hline 3 & --- & 16 & 0.06 \\
\hline 9 & --- & 16 & 0.03 \\
\hline 10 & -- & 16 & 0.26 \\
\hline 11 & --- & 16 & 0.11 \\
\hline 12 & --- & 16 & 0.2 \\
\hline 13 & --- & 16 & 0.02 \\
\hline 14 & -- & 16 & 0.12 \\
\hline 15 & --- & 16 & 0.03 \\
\hline
\end{tabular}




\section{Appendix D}

Network analysis (using EBICglasso) with the German-speaking sample $(N=418)$ including the open-mindedness scale. The network has 22 nodes and 85 non-zero edges out of 231 . Visual inspection of the figure shows four communities (see color's nodes). Positive connections emerged between deliberate mind-wandering and open-mindedness; negative connections emerged between boredom and open-mindedness.

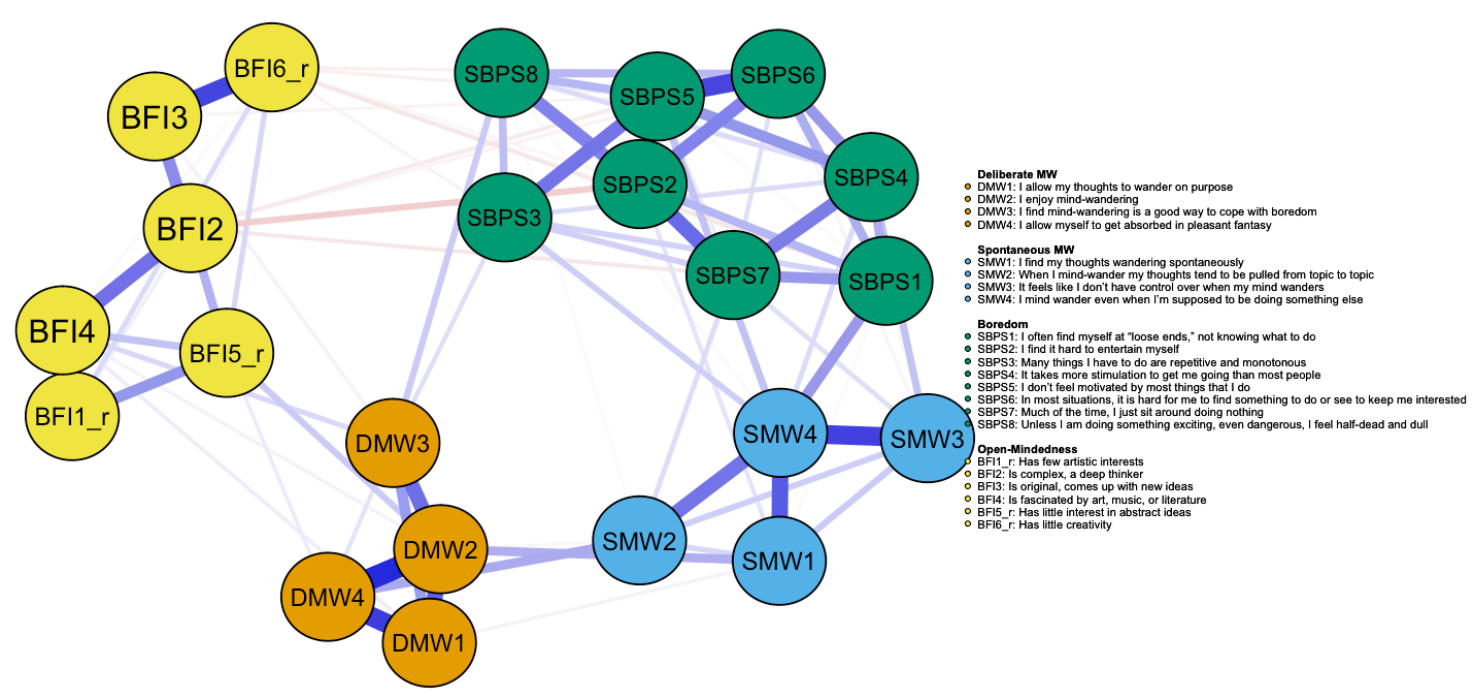

